\title{
Examining Changes In The Strategic Alignment Model's Alignment Factors Over Time: A Case Study
}

Kerry Ward, University of Nebraska, Omaha, USA

\begin{abstract}
The strategic alignment model of Henderson and Venkatraman (1994) views IS alignment as occurring among four factors: business strategy, organization infrastructure and processes, IS strategy, and IS infrastructure and processes. Henderson and Venkatraman view strategic alignment as occurring via "simultaneous or concurrent attention to all four domains." A single case study was conducted to examine how changes in the alignment factors actually occur over time. Our findings suggest that while $H \& V$ indicated the SAM is a descriptive model, it explains few of the changes that actually occurred in the case and has limited applicability as a descriptive model.
\end{abstract}

Keywords: IS Alignment; Strategic Alignment Model; Case Study

\section{INTRODUCTION}

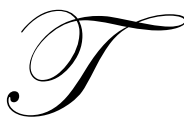

hat strategic IS alignment has long been a significant topic of interest to both the IS professional and academic communities is substantiated by the fact that it has been among the top ten IS issues identified by CIOs over the past several years (see for example, Luftman and Ben-Zvi 2010; Luftman and McLean, 2004; Luftman, 2005; Luftman, Kemppaiah, and Nash, 2006; Watson and Brancheau, 1991; Watson, Kelly, Galliers, and Brancheau, 1997). The commonly-held belief among practitioners and academics is that appropriate IS alignment results in better organizational performance (see, for example, Chan 2002; Chan, Huff, Barclay, and Copeland 1997; Henderson and Venkatraman 1993; Sabherwal and Chan 2001; Sabherwal, Hirschheim, and Goles 2001). Despite the substantial body of accumulated research, the continuing presence of IS alignment on the list of most important issues is evidence that IS alignment and how to achieve it remain illusory.

One of the most prominent works integrating information technology into strategic alignment has been the strategic alignment model (SAM) of Henderson and Venkatraman (1991, 1992, 1993, 1994, 1996). Henderson and Venkatraman (1993) state that IS alignment involves "fit" and "integration" among business strategy, IT strategy, business infrastructure, and IT infrastructure. They indicate that the SAM can be applied as either a descriptive, prescriptive or dynamic model (Henderson and Venkatraman 1994). In this paper, we investigate how the alignment factors actually change over time to examine whether Henderson and Venkatraman's model of alignment explains alignment as it actually occurs in practice, in essence, testing the descriptive nature of Henderson and Venkatraman's strategic alignment model. We used a single case study research design (Benbasat, Goldstein and Mead, 1987; Eisenhardt, 1989; Yin, 1994) and apply pattern matching to evaluate the SAM based on changes in the alignment factors.

In the next section we examine Henderson and Venkatraman's model of strategic alignment and set the scene for the study that we conducted. The research methodology is then presented including a description of the way in which the data was analyzed to investigate the alignment process. Next we present the findings of our study and discuss the implications for both research and practice. 


\section{THE STRATEGIC ALIGNMENT MODEL}

In response to the growing strategic role of information systems in modern organizations, Henderson and Venkatraman developed a framework to conceptualize the strategic use of information technology, which they referred to as the strategic alignment model (see Figure 1). Henderson and Venkatraman present their work on alignment in multiple versions (see, for example, Henderson \& Venkatraman 1991, 1992, 1993, 1994, 1996). These variations address essentially the same basic model with only minor modification to the theoretical content.

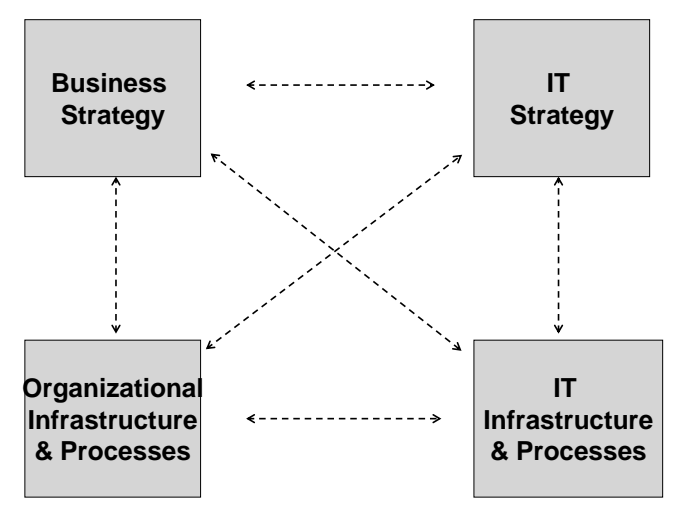

Figure 1.

Strategic Alignment Model

(Adapted from Henderson and Venkatraman 1994)

The SAM explains IT alignment in terms of two components of strategic management: 1) strategic fit and 2) functional integration. The first component, strategic fit, represents how well the internal structures of the firm fit with the firm's strategic positioning. Henderson and Venkatraman indicate that an organization's administrative structure should be designed to support the position of the organization in relation to its competitive product-market arena.

The second component, functional integration, represents the fit of the business and IT functional domains. Henderson and Venkatraman identified four internal functional domains or "alignment factors:" 1) business strategy, 2) information technology strategy, 3) organizational infrastructure and processes, and 4) information technology infrastructure and processes. It is the relationship or "fit" among these functional domains that is the primary focus of Henderson and Venkatraman's strategic alignment model. Based on this fit approach, IT alignment occurs when all the domains attain the appropriate state of uniformity at the same time. True strategic alignment, therefore, requires "simultaneous and concurrent attention to all four domains" (Henderson and Venkatraman 1994 pg. 212).

An underlying assumption of the SAM is that proper alignment is related to performance: when all four factors are in alignment effective performance results. Alternatively, this implies that a firm that is performing well likely has a minimum level of alignment and if one alignment factor changes, this will require changes in each of the other factors to maintain alignment. Hence the model represents an equilibrium state: if one factor changes, all factors should change, otherwise the system will no longer be in alignment.

Since its initial publication, the strategic alignment model has served either directly or indirectly as the foundation for a substantial amount of research on IS alignment. Multiple studies have focused on alignment of the essential elements of business and IT strategy and structure (or pairs of them) (see, for example, Chan 2002; Chan et al. 1997; Sabherwal and Chan 2001; Sabherwal et al. 2001), and on the effect of alignment on organizational performance (see, for example, Chan 2002; Palmer and Markus 2000; Sabherwal and Chan 2001). The focus on "simultaneous and concurrent attention to all four domains" and the substantial body of research examining fit from a cross-section or variance approach has led some to view IS alignment as "synchronization" in which a change in 
one alignment factor is viewed as leading to changes in each of the other factors (Sabherwal, et al. 2001; Smaczny 2001). In this paper, we examine how well this synchronization view of the SAM actually describes changes in the alignment factors.

As noted above Henderson and Venkatraman's notion of strategic fit includes integration with the external market. Therefore, in addition to the four alignment factors, two additional factors related to the broader environment are examined: the external environment and the firm's strategic intent, which reflects the way in which top management is positioning the firm for the future (Lovas and Ghoshal 2001). These two additional factors were included to capture key external drivers for changes in the four traditional alignment factors. Table 1 presents definitions of the factors that we examine in this research.

Table 1. Factors Examined

\begin{tabular}{|l|l|}
\hline \multicolumn{1}{|c|}{ Event } & \multicolumn{1}{c|}{ Description } \\
\hline External environment & Changes external to the company that influence the way in which the company does business \\
\hline Strategic intent & Changes in company goals \\
\hline Business strategy & $\begin{array}{l}\text { Changes in strategic initiatives that represent significant changes in the way the company does } \\
\text { business }\end{array}$ \\
\hline Organization structure & $\begin{array}{l}\text { Changes in the way the organization is structured; defined as changes in organizational structure (as } \\
\text { represented, for example, in the organization chart) or changes in significant management } \\
\text { responsibilities }\end{array}$ \\
\hline IS strategy & Changes in strategic initiatives that represent significant changes in the way the company utilizes IS \\
\hline IS structure & Changes in IS structure and/or processes \\
\hline
\end{tabular}

\section{RESEARCH METHOD}

We conducted an exploratory case study (Yin 1994) by conducting interviews with both top-level business and IS managers as well as collecting archival data for triangulation purposes. The procedures we used to ensure validity and reliability (Yin 1994) are summarized in Table 2.

Table 2. Validation Methods Used

\begin{tabular}{|l|c|c|c|}
\hline \multicolumn{1}{|c|}{ Data Quality Validation Methods (Yin 1994) } & $\begin{array}{c}\text { Construct } \\
\text { Validity }\end{array}$ & $\begin{array}{c}\text { Internal } \\
\text { Validity }\end{array}$ & Reliability \\
\hline Use of Multiple Sources of Evidence & Yes & & \\
\hline Use of Chain of Evidence & Yes & & \\
\hline Member Check (Validation of Case Data Write up by Primary Contact) & Yes & & \\
\hline Examining Change Over Time & & Yes & \\
\hline Use of Iterative Pattern Matching & & Yes & \\
\hline Use of Case Study Protocol & & & Yes \\
\hline Use of Archival Documents & & & Yes \\
\hline
\end{tabular}

The case study site is Farm Products Incorporated (FPI), a closely-held manufacturer of grain storage systems and other farm-related products located in the U.S. mid-west. Since its inception in 1964 as a family run business, the company grew to become one of the largest manufacturers of grain storage and livestock feeding systems in the world. The history of FPI can be viewed in "alignment episodes" that are accentuated by specific drivers. Changes in the alignment factors were examined for each of these episodes. Detailed write ups of the five episodes are available from the author on request but have not been included due to their length.

We analyzed the raw data in an identifiable series of steps. First, we constructed event histories based on changes in the alignment factors from 1987 to the present. This data represents the descriptive raw data on FPI's alignment process. Second a temporal bracketing strategy was used to decompose our event histories into identifiable sets of events, or "episodes." We identified an episode as a period of time between major changes in either strategic intent or strategic initiative because these events give us an opportunity to observe changes in the 
alignment factors. Hence episodes were identified as periods that led to "continuity in the activities within each period," and that were discontinuous with "adjacent" episodes (Langley 1999) providing the opportunity to determine whether there was a relationship among the observed changes in the alignment factors. Table 3 summarizes the inter-relationships among the factors in the alignment system over the five episodes.

Table 3: Pattern of Inter-Related Events in Alignment Episodes

\begin{tabular}{|c|c|c|c|}
\hline Episode/Time Period & Event & Links among Events $(\rightarrow)$ & \# Related Events \\
\hline $\begin{array}{c}\mathbf{1} \\
(1987-1993)\end{array}$ & $\begin{array}{l}\text { EE-1 } \\
\text { SI-1 } \\
\text { OS-1 } \\
\text { ISP-1 } \\
\text { ISP-1 }\end{array}$ & SI-1 $\rightarrow$ OS-1 & 1 \\
\hline $\begin{array}{c}\mathbf{2} \\
(1993-1996)\end{array}$ & $\begin{array}{l}\text { SI-2 } \\
\text { OS-2 } \\
\text { ISP-3 }\end{array}$ & SI-2 $\rightarrow$ OS-2 & 1 \\
\hline $\begin{array}{c}\mathbf{3} \\
(1996-1997)\end{array}$ & $\begin{array}{l}\text { SI-3 } \\
\text { OS-3 } \\
\text { ISP-4 } \\
\text { ISP-5 }\end{array}$ & $\begin{array}{l}\text { SI-3 } \rightarrow \text { OS-3 } \\
\text { OS-3 } \rightarrow \text { ISP-5 }\end{array}$ & 2 \\
\hline $\begin{array}{c}\mathbf{4} \\
(1997-1998)\end{array}$ & $\begin{array}{l}\text { EE-2 } \\
\text { EE-3 } \\
\text { EE-4 }\end{array}$ & $(\mathrm{EE}-2 \rightarrow) \mathrm{OS}-4$ & 0 \\
\hline $\begin{array}{c}\mathbf{5} \\
(1998-2001)\end{array}$ & $\begin{array}{l}\text { EE-5 } \\
\text { S-2 } \\
\text { OS-5 } \\
\text { OS-6 } \\
\text { OS-7 } \\
\text { ISP-6 }\end{array}$ & $\begin{array}{l}(\text { EE-3, EE-4 } \rightarrow \text { )S-2 } \\
\text { S-2 } \rightarrow \text { OS-5 } \\
\text { S-2 } \rightarrow \text { OS-6 } \\
(\text { EE-5 } \rightarrow \text { )OS-7 } \\
\text { OS-5 } \rightarrow \text { ISP-6 }\end{array}$ & 3 \\
\hline
\end{tabular}

In the third step, a visual mapping strategy was applied to show the inter-relationships of the events across all six factors for each of the episodes (see Figure 2). Such a strategy facilitates the parsimonious presentation of large quantities of information and the development and verification of theoretical ideas (Langley 1999). The dotted line between change events represents a relationship between the events where one change lead to or result in another change event.

Finally, we used a pattern matching strategy to assess the notion of alignment derived from the above discussion of the SAM. Such an approach is deductive in nature. The researcher develops an interpretation based on an established theoretical premise, develops an expected pattern in the data and then matches the pattern derived from the data to the predicted pattern to see if they are similar. Table 3 presents the five episodes in terms of the events that constitute them and the triggers responsible for them.

As we have seen, the prior literature suggests that for IS alignment to occur, changes in the business strategy and structure and IS strategy and structure must, in effect, be synchronized. Assuming that a minimum level of alignment existed based on the performance of FPI, one would expect to see a series of episodes in which the organization is brought back into alignment following a change in one of the factors.

We analyze the changes by episodes, each of which represents a major alignment opportunity. In doing so, note that we are able to identify not only simultaneous and concurrent changes, but also time delays in the firm's reaction to change, which would be evidenced by a stair-step pattern of related events within an episode. 


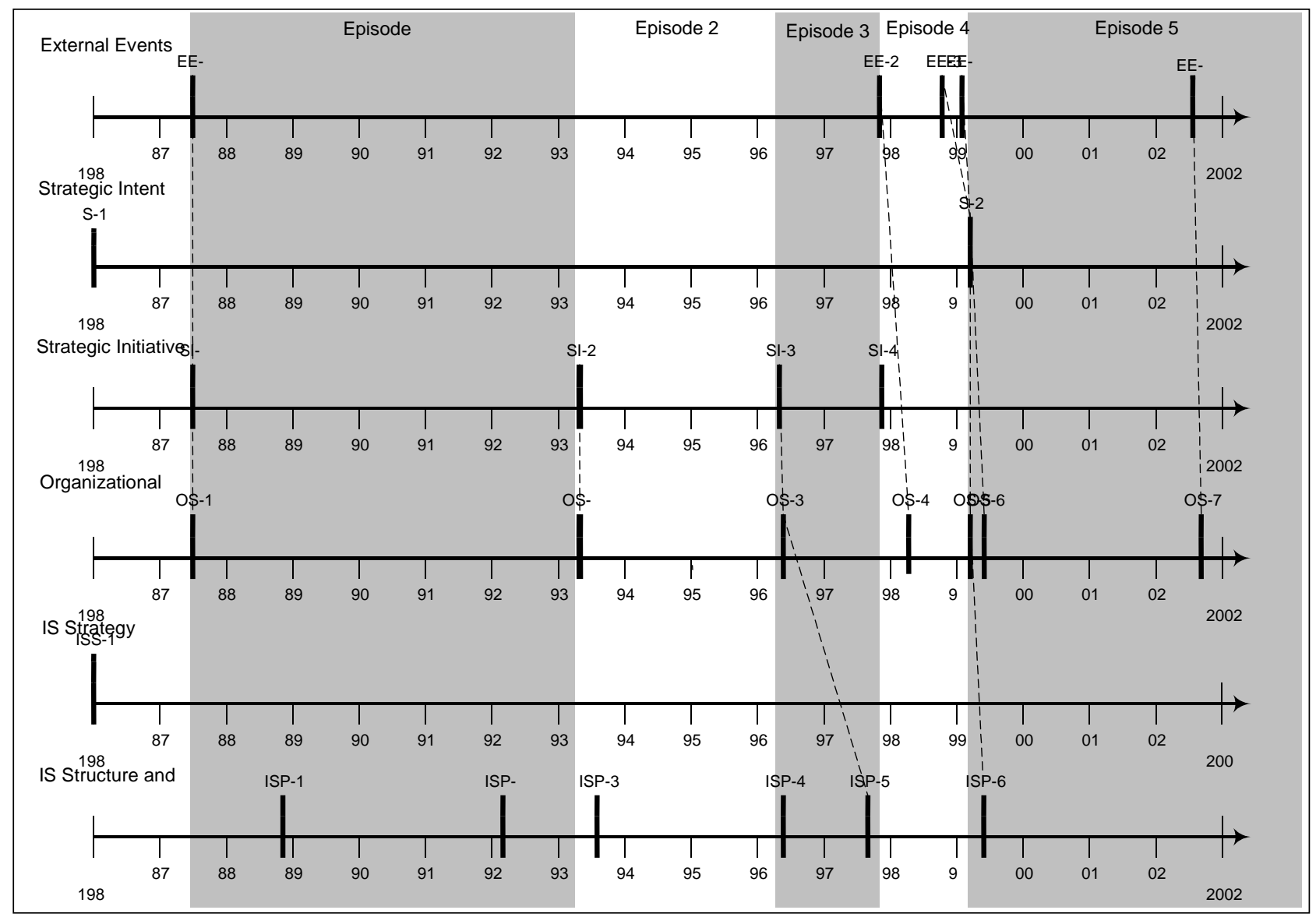

Figure 2: Timeline and Inter-Relationships of Events

\section{RESULTS}

A review of Figure 2 does not reflect a pattern of interconnected change running throughout the factors in an episode (or even a majority of them). Few changes throughout the various organizational levels are strongly related to each other, and a change in one factor may or may not be related to changes in other factors in the same episode (see "Links among Events" in Table 4 and timing in Figure 2). Note that there are 6 possible interactions per episode. Hence, the number of expected inter-relationships among the alignment factors over 5 episodes is 30 . Only 7 of those possible inter-relationships were observed at FPI.

While Episode 5 resulted in substantial changes, those changes resulted from the change in strategic intent, and not from inter-related changes in the four alignment factors. The change in strategic intent was motivated by a number of major hurdles in FPI's external environment: the U.S. market for pork collapsed (EE-3), an event that was followed by the financial crisis in Asia (EE-4). Due to its changed economic circumstances, FPI changed its strategic intent from a focus on growth to a focus on efficiency/profitability (S-2).

Neither do the other episodes illustrate "simultaneous and concurrent" events flowing through the four alignment factors. Episode 2, for example, from 1993 to 1995 was initiated when FPI diversified its product line from grain bin manufacture to livestock feeding and equipment manufacture by acquisition of manufacturing companies in those industries (SI-2). As a result, FPI established additional divisions for its poultry and livestock product lines (OS-2). However, there were no substantive changes in IS structure and processes; that is, the company felt that it could manage its new product lines with existing systems and software. Hence just two events were linked in this episode. 
Episode 3, from 1996 to 1997, represents the most "connected episode of the seven we identified. It was characterized by the expansion of sales of its more recent product lines, poultry and livestock feeding and production equipment, into international markets (SI-3). As a result, regional sales offices were established in a number of countries, such as the Netherlands, Malaysia, and South Africa, among others (OS-3). The company instituted the use of the MAS-90 software package to support the new sales operations. Hence three inter-related events took place during this episode, resulting in the two links shown in Table 3. During this time frame, the company also engaged in major customizations to its MRP software (QMRP). The driver for this IS initiative was not, however, the expansion of the company's sales activities, but the result of a company investigation of ERP package capabilities - a non-related event.

Although we allowed for some time delay in "simultaneous and concurrent" changes in the alignment factors by examining inter-related changes that occurred during an episode, we also examined the possibility that a change in strategic initiative, for example, does require re-alignment, but that a more significant time delay might be experienced before that occurs. In this case, the inter-related event might occur in a later episode. Perusal of Figure 2, however, does not support this notion: there are no links across episodes in Figure 2. Hence, it is clear, then, that changes in strategic initiative most frequently do not lead changes in other factors. In particular, at FPI, changes in IS strategy and structure rarely followed changes in strategic initiative. While substantial changes in IS structure did occur throughout FPI's history, the majority of them were not directly related to the other factors. In fact, as noted above, we identified only one instance where a change in IS structure and processes resulted from a change in organization structure (see Episode 3).

This research is not without limitations. First, we used interview data to capture historical events. To minimize the potential effects of using such data, when available, we triangulated our record of events derived from interviews with evidence obtained via documentation such as SEC filings. Second, the generalizability of qualitative data is limited to theory and no statistical generalizability is claimed (Lee and Baskerville 2003).

\section{CONCLUSION}

This research indicates that applying Henderson and Venkatraman's SAM as a descriptive model does not explain the changes in the alignment factors at our case site. In fact, very few changes in business and IS strategy and structure are inter-linked, with IS structure and process events being perhaps the least connected of the different types of events.

It is important to note, however, that this research focuses on Henderson and Venkatraman's notion of fit and their statement that alignment requires "simultaneous or concurrent" attention to all four domains or what others have referred to as "synchronization." IT can be argued that this interpretation is a misappropriation of Henderson and Venkatraman's SAM that results from the common use of cross-sectional, variance oriented methodologies applied to study the SAM. And indeed, Henderson and Venkatraman (1994) conceived of the "strategic alignment model as a dynamic model of strategic IT management." The conclusion to be drawn from this research, therefore, is that we need to move from the variance oriented, cross-sectional approaches which have dominated the alignment research, particularly as applied to Henderson and Venkatraman's SAM, to focus on the dynamic nature of alignment and, perhaps most important, how to sustain it over time.

The most important implication of our research is demonstrating that a well-established assumption regarding the alignment process does not stand up to empirical scrutiny, thereby opening the way to further studies of the process by which alignment actually occurs. Researchers should focus on developing theory that explains the process by which alignment actually occurs. Such theory would have far-reaching consequences for IS researchers, given the high-levels of interest that the practitioner community has shown in alignment.

For a number of years, IS research has contributed little to the practitioner community perhaps because of a lack of focus on alignment process and perhaps because of its search for alignment in the context of synchronization among the alignment factors. There is now an opportunity to speak to practitioners by adopting a more realistic view of the alignment as a dynamic process as Henderson and Venkatraman suggested all along. 


\section{AUTHOR INFORMATION}

Kerry Ward is an assistant professor in the Information Systems and Quantitative Analysis department at the University of Nebraska - Omaha. Kerry's research interests include IS strategy, knowledge management and research methods. His work has been published in the International Journal of Business Information Systems and the Journal of Information Systems Technology and Planning. He is a CPA with seven years' experience in consulting and public accounting with Deloitte and Touché and PriceWaterhouseCoopers. E-mail: kwward@mail.unomaha.edu

\section{REFERENCES}

1. Benbasat, I., Goldstein, D. K. and Mead, M. "The Case Research Strategy in Studies of Information Systems," MIS Quarterly (11:3), 1987, pp. 369-386.

2. Chan, Y., Huff, S., Barclay, D., and Copeland, D. "Business Strategic Orientation, Information Systems, Strategic Orientation, and Strategic Alignment," Information Systems Research, (8:2), 1997, pp. 125-150.

3. Chan, Y. E. "Why Haven't We Mastered Alignment? The Importance of the Informal Organizational Structure," MIS Quarterly Executive (1:2), 2002, pp. 97-112.

4. Eisenhardt, K. M. "Building Theories from Case Study Research." Academy of Management Review, (14:4), 1989, pp. 532-550.

5. Henderson, J.C., Venkatraman, N. and Oldach, S., "Aligning Business and IT Strategies". In Luftman, J.F., Competing in the Information Age: Strategic Alignment in Practice. Oxford University Press, New York, 1996, pp.21-42.

6. Henderson, J. C., N. Venkatraman. Strategic alignment: a model for organizational transformation via information technology. T.J. Allen, M.S. Scott-Morton, eds. Information Technology and the Corporation of the 1990s. Oxford University Press. UK. 1994, 202-220.

7. Henderson, J.C. and Venkatraman, N. "Strategic Alignment: A Model for Organizational Transformation Through Information Technology". In Kochan, Thomas A. and Useem, Michael, editors, Transforming Organizations, Oxford University Press, New York, 1993, pp. 97-117.

8. Henderson, J.C. and Venkatraman, N., "Strategic Alignment: Leveraging Information Technology for Transforming Organizations," IBM Systems Journal, (32:1), 1993, pp. 4-16.

9. Henderson, J. and Venkatraman, N., "Strategic Alignment: A Model for Organizational Transformation via Information Technology." In T.J. Allen and M.S. Scott-Morton (eds.), Information Technology and the Corporation of the 1990s, Oxford University Press, UK, 1992, pp. 202-220.

10. Henderson, J. and Venkatraman, N., "Understanding Strategic Alignment," Business Quarterly, (56:3), 1991, pp. 72-78.

11. Langley, A. "Strategies for Theorizing from Process Data," Academy of Management Review (24:4), 1999, pp. 691-710

12. Lovas, B. and Ghoshal, S., "Strategy as Guided Evolution," Strategic Management Journal, 21, 2001, pp. 875-896.

13. Luftman, J. Key Issues For IT Executives 2004. MISQ Executive, (4:2), 2005, 269-285.

14. Luftman, J. \& Ben-Zvi, T.. Key Issues For IT Executives 2009: Difficult Economy's Impact On IT. MISQ Executive, (9:1), 2010, 49-59.

15. Luftman, J. \& Brier, T. Achieving And Sustaining Business IT Alignment. California Management Review, (42:1), 1999, 109-122.

16. Luftman, J., Kempaiah, R. \& Nash, E. Key Issues For IT Executives 2005. MISQ Executive, (5:2), 2006, 81-99.

17. Luftman, J. \& McLean, E.R.. Key Issues For IT Executives. MISQ Executive, (3:2), 2004, 89-104.

18. Palmer, J. and Markus, M.L., "The Performance Impacts of Quick Response and Strategic Alignment in Specialty Retailing," Information Systems Research, (11:3), 2000, pp. 241-259.

19. Sabherwal, R., R. Hirschheim, and Goles, T. "The Dynamics of Alignment: Insights from a Punctuated Equilibrium Model," Organization Science (12:2), 2001, pp. 179-197.

20. Sabherwal, R. and Chan, Y. E. "Alignment Between Business and IS Strategies: A Study of Prospectors, Analyzers, and Defenders." Information Systems Research (12:1), 2001, pp. 11-33. 
21. Smaczny, T., "Is an Alignment Between Business and Information Technology the Appropriate Paradigm to Mange IT in Today's Organizations?" Management Decision (39:10), 2001, pp. 797-802.

22. Watson, R. and Brancheau, J. C., "Key Issues in Information Management: An International Perspective," Information and Management, (20:3), 1991, pp. 213-223.

23. Watson, R., Kelly, G. G., Galliers, R. D., and Brancheau, J. C., "Key Issues in Information Systems Management: An International Perspective," Journal of Management Information Systems, (13:4), 1997, pp. 91-115.

24. Weill, P and Broadbent, M, "Developing Business and Information Strategy Alignment: A Study in the Banking Industry," International Conference on Information Systems, 1991, 293-306.

25. Yin, R. K. Case Study Research: Design and Methods. Sage, Thousand Oaks, CA, 1994. 